Noble, Perline, and Stoldt

The Big East Breakup: Effects on Competitive Balance

\author{
Jeffrey Noble \\ Wichita State University \\ Martin M. Perline \\ Wichita State University \\ G. Clayton Stoldt \\ Wichita State University
}




\begin{abstract}
Whereas much of the research on competitive balance deals with the addition of one or more members to a conference and compares the competitive balance before and after the addition(s), the authors of this study investigated competitive balance in men's basketball, using the extreme case of the breakup of the Big East Conference, which led to a reconstituted Big East Conference and the formation of the American Athletic Conference (AAC). Given that the reconstituted Big East Conference had basically chosen its members, whereas the AAC need to scramble around to replace its departing members, it was hypothesized that the reconstituted Big East Conference would have a more competitively balance conference than the newly formed AAC. Using the standard deviation, it was discovered that competition among men's basketball teams displayed more competitive balance in the reconstituted Big East conference than in the AAC.
\end{abstract}




\section{The Big East Breakup: Effects on Competitive Balance}

Fan interest in competitive sports is linked, at least in part, to competitive balance (Depken \& Wilson, 2006; El Hodiri \& Quick, 1971; Jane 2016; Kesenne, 2006; Knowles, Sherony \& Haupert, 1992; Paul \&Wilson, 2015; Quick \& Fort, 1992; Sanderson \& Siegfried, 2003). Whether the games are professional or amateur, some degree of uncertainty regarding the outcome is necessary to sustain fan interest. Otherwise, fan attrition is likely, and thus a decrease in revenues from both attendance and media to the organizations (Ahn \& Lee, 2014). Stated somewhat differently, it is of vital importance that for any sports league or conference, there is the necessity that there be some degree of competitive balance among the various teams. The importance of competitive balance was discussed as early as 1956 when Simon Rottenberg pointed out with the "uncertainty of outcome hypothesis" that successful leagues required some degree of parity. (Rottenberg, 1956).

At the professional level, measures such as revenue sharing, salary caps, and reverse order finish for draft choice attempt to bring about more competitive balance. At the college level, regulations imposed by the national governing organization, i.e., NCAA, NAIA, have attempted to promote competitive balance with rules and regulations such as scholarship limits, prohibitions against extra benefits offered to student athletes, etc. (Rhoads, 2004). Conferences also play a role in promoting competitive balance. And as conferences seek to maximize their revenue potential via changes in membership, changes in competitive balance may be expected (Rhoads, 2004). Most commonly in college sports, football and men's basketball are primary drivers of conference and member revenue (e.g., ticket sales, television rights fees). Therefore, the need for competitive balance, particularly in those two sports, is an important consideration whenever changes in conference membership are considered. Arguably, much of the conference realignment over the past few years can be linked to competitive balance.

In order to shed light on this issue we investigated the extreme case of the breakup of the Big East Conference which led to a reconstituted Big East Conference, and the formation of the American Athletic Conference. In this case seven schools which were members of the original Big East Conference broke off (Georgetown, Marquette, Villanova, Providence, St. John's, Seton Hall and De Paul), added three additional schools (Creighton, Xavier, and Butler), and started their own conference. Ironically, the namethe Big East Conference, remained with these schools, while the remaining schools became the American Athletic Conference. Meanwhile before the start of the 2013-14 season three schools left the new AAC (Pittsburgh, Syracuse, and Notre Dame), and five were added (Memphis, Southern Methodist, Houston, Central Florida, and Temple). Then before the start of the 2014-15 season Louisville and Rutgers also departed the conference.

To the extent that conference realignments are at least partially driven to achieve greater competitive balance, it could be suggested that the breakaway institutions, i.e., reconstituted Big East, (hereafter referred to merely as the Big East) could "cherry pick" those institutions which would permit them to achieve this goal. On the other hand, the $\mathrm{AAC}$, those institutions remaining in the original Big East, needed to scramble to find replacements for the departing schools in order to maintain a viable conference, and consequently, would have a more difficult time achieving competitive balance. Thus, one 
could hypothesize that the Big East should have a more competitively balanced conference than the AAC.

\section{Literature Review}

\section{The Big East and American Athletic Conferences}

The original Big East Conference was formed in 1979, initiated by the NCAA's newly imposed in-season scheduling requirements for men's basketball. The athletic directors of Syracuse, Providence, Georgetown, and St. John's met with the intention to establish a conference of schools situated in northeastern United States. They invited Boston College, Connecticut, Holy Cross, Rutgers, and Seton Hall to join in the formation of the new conference, but Rutgers and Holy Cross declined (Crouthamel, 2000). By 1982, Villanova and Pittsburgh had joined, and the conference maintained those nine members for roughly the next decade (Gall, 2013).

Primarily a basketball conference, the Big East began to sponsor football in 1991 with the addition of Miami, Rutgers, Temple, Virginia Tech, and West Virginia. This essentially divided the conference into "football" and "non-football" schools, which over time created instability amongst the institutions. In 2003, three of the "football" schools - Boston College, Miami, and Virginia Tech - left the Big East to join the Atlantic Coast Conference (ACC), while five schools left Conference USA (Louisville, Cincinnati, DePaul, Marquette, South Florida) to join the Big East (Gall, 2013).

Beginning in 2010 and continuing through 2013, the Big East, like many conferences during that period, experienced numerous changes. Overall, 13 schools - mostly programs with Football Bowl Subdivision (FBS) teams, including West Virginia, Syracuse, and Pittsburgh - left to join other conferences (Gall, 2013). In 2013 the remaining non-FBS schools (DePaul, Georgetown, Marquette, Providence, Seton Hall, St. Johns, Villanova) broke away from the conference as a group. Initially labeled the Catholic 7, they later negotiated for the rights of the Big East name, along with the rights to hold their basketball tournament at Madison Square Garden (Harten, 2013). Joining them in the new Big East Conference were Creighton, Butler, and Xavier.

The remaining FBS schools (Cincinnati, Connecticut, and South Florida) joined up as the newly formed American Athletic Conference (AAC), which eventually included Central Florida, East Carolina, Houston, Memphis, Navy, Southern Methodist, Temple, Tulsa, and Tulane (McMurphy, Katz \& O'Neal 2012). The AAC underwent another change in membership in 2014-15. Louisville left to join the Atlantic Coast Conference, and Rutgers departed for the Big 10. Meanwhile Tulsa, Tulane, and East Carolina left Conference USA to join the AAC.

\section{Competitive Balance in College Basketball}

The majority of competitive balance-related studies in college athletics have focused on football. However, a number of researchers have examined various dimensions of competitive balance in men's basketball. In an analysis of membership changes in the Western Athletic and Mountain West conferences over a 40-year period, Rhoads (2004) considered the influence of men's basketball in driving conference realignment. The rationale for this study was that previous researchers such as Fort and Quick (1999) had focused on football as a driver of churning among college conferences. Rhoads accounted 
for the impact of football in the analysis. The resultant conclusion was that while changes in conference membership led to enhanced competitive balance in football, the same was not true of men's basketball.

Perline and Stoldt (2007) compared levels of competitive balance between men's basketball and women's basketball in the Missouri Valley Conference (MVC). Noting that men's basketball tends to generate more revenue than women's basketball, they hypothesized that higher levels of competitive balance would be found in the men's game. Analysis of data from a 10-year period supported this hypothesis with three different measures, including the standard deviation of winning percentages, indicating more competitive balance in MVC men's basketball than women's. The MVC was also the focus of a study by Perline and Stoldt (2008), which examined changes in competitive balance before and after the 1992 merger of the Gateway Collegiate Athletic Conference with the MVC. Using the same set of measures as in their previous study of the MVC, the authors found mixed results with arguably a slight gain in competitive balance after the merger.

Treber, Levy and Matheson (2013) compared competitive balance between men's and women's basketball in national championship tournaments. Using measures from NCAA tournaments such as margin of victory and winning percentage by seed levels, they too found greater competitive balance in men's basketball than women's at the Division I level. In a related finding, Treber et al reported that competitive balance in the men's tournament had improved when comparing the 1952-1981 and 1982-2011 time periods.

Perline, Noble and Stoldt (2017) conducted an additional study comparing competitive balance in men's and women's basketball programs, this time focusing on the Power 5 conferences, as commonly referenced. In their analysis of data from five years of competition, the authors employed multiple measures of competitive balance, including the standard deviation of winning percentages and actual standard deviation/ideal standard deviation ratio. Their findings again indicated higher levels of competitive balance in men's basketball, an expected result, the authors argued, given typically higher levels of revenue associated with the men's sport.

\section{Methods}

\section{Measuring Competitive Balance}

In order to measure competitive balance researchers have relied on several statistical approaches, depending on whether the analysis was measuring "within season", or "between season" variation. Possibly the method most often used to measure competitive balance in a conference within a given season, which is what is attempted in this analysis, is the standard deviation (Leeds \& Von Allmen, 2014). This statistic measures the average distance that observations lie from the mean of the observations in the data set.

In any conference game absent a tie, there will be one winner and one loser. Therefore, within conference competition, the mean winning percentage will always be .500 . Analysis of the dispersion of team standard deviations around the conference mean provides perspective regarding competitive balance. If every team had a winning percentage of .500, the standard deviation would be zero and the highest possible level of competitive balance would exist.

The less dispersion of winning percentages around the mean, the lower the standard deviation and the higher the competitive balance While there are other methods used to 
measure competitive balance, (e.g., Barra, 2002), the standard deviation appears to be the one most often chosen.

\section{Standard Deviation Formula}

The formula for the standard deviation of winning percentages is as follows:

$$
\sigma=\frac{\sqrt{\Sigma(\mathrm{WPCT}-.500)^{2}}}{\mathrm{~N}}
$$

where the WPCT is the winning percentage of each team in the conference for a given year, .500 is the average winning percentage for all teams for that year, and $\mathrm{N}$ is the number of teams in the league.

For comparative purposes one could calculate an ideal standard deviation which would be a situation where each team had a 0.5 chance of winning each game. In our case one could see how far from the ideal, the actual standard deviation varied. The equation is

$$
\sigma=0.5 / \sqrt{ } \mathrm{N}
$$

where .5 indicates that each team has a 0.5 probability of winning, and $\mathrm{G}$ is the number of games each team plays.

\section{Results and Discussion}

Tables 1-2 display the winning percentages for the conferences under consideration. Table 3 displays the standard deviations for the respective conferences.

Table 1

Big East Conference Standings

\begin{tabular}{lccccccccccccc} 
& \multicolumn{3}{c}{} & \multicolumn{1}{c}{$2013-14$} & \multicolumn{2}{c}{$2014-15$} & \multicolumn{2}{c}{$2015-16$} & \multicolumn{2}{c}{$2016-17$} \\
Teams & W & L & PCT & W & L & PCT & W & L & PCT & W & L & PCT \\
\hline Villanova & 16 & 2 & .889 & 16 & 2 & .889 & 16 & 2 & .889 & 15 & 3 & .833 \\
Creighton & 14 & 4 & .777 & 4 & 14 & .222 & 9 & 9 & .500 & 10 & 8 & .556 \\
Providence & 10 & 8 & .556 & 11 & 7 & .611 & 10 & 8 & .556 & 10 & 8 & .556 \\
Xavier & 10 & 8 & .556 & 9 & 9 & .500 & 14 & 4 & .778 & 9 & 9 & .500 \\
St. John's & 10 & 8 & .556 & 10 & 8 & .556 & 1 & 17 & .056 & 7 & 11 & .389 \\
Marquette & 9 & 9 & .500 & 4 & 14 & .222 & 8 & 10 & .444 & 10 & 8 & .556 \\
Georgetown & 8 & 10 & .444 & 12 & 6 & .667 & 7 & 11 & .389 & 5 & 13 & .278 \\
Seton Hall & 6 & 12 & .333 & 6 & 12 & .333 & 12 & 6 & .667 & 10 & 8 & .556 \\
Butler & 4 & 14 & .222 & 12 & 6 & .667 & 10 & 8 & .556 & & &
\end{tabular}


Noble, Perline, and Stoldt

$\begin{array}{llllllllll}\text { De Paul } & 3 & 15 & .166 & 6 & 12 & .333 & 3 & 15 & .166\end{array}$

Table 2

American Athletic Conference Standings

\begin{tabular}{lcccccccccccc} 
& \multicolumn{3}{c}{} & \multicolumn{1}{c}{$2013-14$} & \multicolumn{2}{c}{$2014-15$} & \multicolumn{2}{c}{$2015-16$} & \multicolumn{2}{c}{$2016-17$} \\
Teams & $\mathrm{W}$ & $\mathrm{L}$ & $\mathrm{PCT}$ & $\mathrm{W}$ & $\mathrm{L}$ & $\mathrm{PCT}$ & $\mathrm{W}$ & $\mathrm{L}$ & $\mathrm{PCT}$ & $\mathrm{W}$ & $\mathrm{L}$ & $\mathrm{PCT}$ \\
\hline Louisville & 15 & 3 & .833 & & & & & & & & & \\
Cincinnati & 15 & 3 & .833 & 13 & 5 & .722 & 12 & 6 & .667 & 16 & 2 & .889 \\
Connecticut & 12 & 6 & .667 & 10 & 8 & .556 & 11 & 7 & .611 & 9 & 9 & .500 \\
Memphis & 12 & 6 & .667 & 10 & 8 & .556 & 8 & 10 & .444 & 9 & 9 & .500 \\
S. Methodist & 12 & 6 & .667 & 15 & 3 & .833 & 13 & 5 & .722 & 17 & 1 & .944 \\
Houston & 8 & 10 & .444 & 4 & 14 & .222 & 12 & 6 & .667 & 12 & 6 & .667 \\
Rutgers & 5 & 13 & .278 & & & & & & & & & \\
C. Florida & 4 & 14 & .222 & 5 & 13 & .278 & 6 & 12 & .333 & 11 & 7 & .611 \\
Temple & 4 & 14 & .222 & 13 & 5 & .722 & 14 & 4 & .778 & 7 & 11 & .389 \\
S. Florida & 3 & 15 & .167 & 3 & 15 & .167 & 4 & 14 & .222 & 1 & 17 & .056 \\
Tulsa & & & & 14 & 4 & .778 & 12 & 6 & .667 & 8 & 10 & .444 \\
Tulane & & & & 6 & 12 & .333 & 3 & 15 & .167 & 3 & 15 & .167 \\
E. Carolina & & & & 6 & 12 & .333 & 4 & 14 & .222 & 6 & 12 & .333
\end{tabular}

Table 3

Standard Deviations for Conferences

Standard Deviation

$\begin{array}{llllll} & 2013-14 & 2014-15 & 2015-16 & 2016-17 & \text { Average } \\ \text { Big East } & .213825 & 208063 & .242126 & .190853 & .213717 \\ \text { AAC } & .249664 & 230858 & .217106 & .259377 & .239251\end{array}$


As indicated in table 3 for the 2013-14 season, the lowest standard deviation, and thus the most competitively balanced was the Big East with a standard deviation of .214. For the AAC the standard deviation was .250. When comparing the standard deviation for the Big East and the AAC, our expectations were realized. Indeed, the difference in the standard deviation was approximately fifteen percent lower for the Big East. As indicated above this result was not surprising given the fact that the Big East was able to basically pick the teams they wanted in the conference, whereas the AAC was left somewhat scrambling to put together a viable conference after losing seven member of the original Big East conference, and an additional five members before the start of the 2014-15 season. When compiling data for the 2014-15, we found our results were similar to the 2013-14 season with the Big East again having a considerably lower standard deviation than the AAC. In the case of the Big East the standard deviation was .208, and for the AAC it was .231 , an approximate $10 \%$ differential. Interestingly enough, the change in membership had minimal effect on the conference competitive balance since Louisville was on the high end and Rutgers on the low end of the 2013-14 standings, whereas the replacements found Tulsa on the high end of the 2014-15 standings with both Tulane and East Carolina on the low end.

When comparing the standard deviation of the two conferences for the 2015-16 season the results were somewhat surprising, given our original hypothesis. In this case the AAC had a lower standard deviation, i.e., more competitive balance than the Big East. The standard deviation for the former was.217, whereas the standard deviation for the Big East had risen to .242 . Since there were no changes in membership in either conference during this season, there was no explanation that immediately stood out to explain this conclusion. While there were differences in the actual standings, there were relatively few teams that significantly changed their position in the standings. While the deviation in 2015-16 was somewhat surprising, data for the 2016-17 season tended to once again re-enforce the original hypothesis. In that season the Big East had its lowest standard deviation over the four-year period, .191, whereas the AAC had a standard deviation of .259 its highest over the period studied.

In order to avoid the peculiarities which can create deviations for a particular year, we also calculated a mean standard deviation over the four-year period since the breakup of the original Big East. Over the period 2013-14 to 2016-17 the average standard deviation of the Big East Conference was .214 compared to a standard deviation of .240 for the AAC. This was slightly more than a $12 \%$ differential for the four-year period, and supported the original hypothesis.

\section{Conclusions}

In general, using the standard deviation as our measure of competitive balance, our hypothesis that the Big East Conference would be more competitively balanced than the AAC was suggested by the data, as the Big East Conference was more competitively balance in three of the four years under consideration. The only instance in which the AAC had a more competitively balanced conference than the Big East was in 2015-16. The mean standard deviation over the four-year period studied was .214 for the Big East Conference, and .240 for the AAC. 


\section{Limitations}

Given the recent reconfiguration of the conferences under investigation, we could only test our hypothesis for four years. Assuming stable membership (a big assumption in the current climate) more robust analysis will be possible as seasons accrue.

In addition, variation in the conference schedules may be a limiting factor. Given the conference's size, not all AAC teams play the same within conference schedule each year or even year-to-year. It is not a true round-robin, as is sometimes the case with other conferences. Other factors such as injuries, etc. could influence our results. Unfortunately, it is almost impossible to account for all such possibilities.

Further and pertaining to realignment, it is important to recognize that competitive balance, or even related revenue potential, is not the only factor impacting membership decisions. Variables such as geography, academic classifications, and other factors may also be factors. However, given the links among competitive balance, fan interest and revenue, particularly for the sports of football and men's basketball, balance is an important issue. Since the Big East does not play football, it was impossible to test our hypothesis for that sport.

\section{References}

Ahn, C. S. \& Lee, Y. H. (2014). Major League Baseball attendance: Long term analysis using factor models. Journal of Sports Economics, 15 (5), 451-477.

Barra, A. (2002). Clearing the bases. New York: St. Martin's Press.

Crouthamel, J. (2000, December 8). A Big East history and retrospective (Part 1). Retrieved from http://cuse.com/sports/2001/8/8/history.aspx

Depken II. C.A. \& Wilson, D. (2006). Enforcement and competitive balance in college football. The Southern Economic Journal, 72 (4), 826-845.

El-Hodiri, M. \& Quirk, J. (1971). An economic model of professional sports league. Journal of Political Economy, 79 (6), 1302-1319.

Fort, R. \& Quick, J. (1999). The college football industry. In J. Fizel, E. Gustafson, \& L. Hadley (Eds.). Sport economics: Current research (pp. 11-26). Westport, CT: Praeger.

Gall, B. (2013, July 3). History of Big East realignment: Birth of the American Athletic Conference. Retrieved from http://athlonsports.com/college-football/history-big-eastrealignment-birth-american-athletic-conference

Harten, D. (2013, March 5). Catholic 7 has framework to keep Big East name, MSG as tourney site. Retrieved from http://collegebasketball.nbcsports.com/2013/03/05/catholic-7-has-framework-to-keepbig-east-name-msg-as-tourney-site/

Jane, W. (2016). The effect of star quality on attendance demand: The case of the National Basketball Association. Journal of Sports Economics, 17(4), 396-417.

Kesenne,S. (2006) Competitive balance in team sports and the impact of revenue sharing. Journal of Sport Management, 20, 39-51. 
Knowles, G., Sherony, K., and Haupert M (1992). The demand for Major League Baseball: A test of the uncertainty of outcome hypothesis. The American Economist, 36, 72-80.

Leeds, M. \& Von Allmen, P. (2014). The economics of sports. Boston: Pearson-Addison Wesley.

McMurphy, B, Katz, A., \& O’Neal, D. (2012, December 12). Sources: 7 leaning to leave Big East. Retrieved from http://espn.go.com/college-sports/story/_id/8742607/sevencatholic-schools-leaning-leaving-big-east-sources-say

Paul, R.J. \& Wilson, M (2015). Political correctness, selection bias, and the NCAA basketball tournament. Journal of Sports Economics, 4 (4), 255-279.

Perline, M.M., \& Stoldt, G.C. (2007). Competitive balance in men's and women's basketball: The case of the Missouri Valley Conference. The Sport Journal, 10 (2). http://www.thesportjournal.org/2007Journal/Vol10-No4/04Stoldt.asp.

Perline, M.M. \& Stoldt, G.C. (2008). Competitive balance in women's basketball: The Gateway Collegiate Athletic Conference and Missouri Valley Conference merger. Women in Sport and Physical Activity Journal, 17(2), 42-49.

Perline, M.M., Noble, J., \& Stoldt, G.C. (2017). Competitive balance in the power conferences: The case of men's and women's basketball. Paper accepted for presentation at the 2017 Sport \& Society Research Network Conference, London, England.

Quirk, J. \& Fort, R. D. (1992). Pay dirt: The business of professional team sports. Princeton, NJ: Princeton University Press.

Rhoads, T. A. (2004). Competitive balance and conference realignment in the NCAA. Paper presented: $74^{\text {th }}$ Annual Meeting of the Southern Economic Association, New Orleans, LA.

Rottenberg, S. (1956). The baseball players' labor market. Journal of Political Economy, $64,242-258$.

Sanderson, A.R. \& Siegfried, J.J. (2003) Thinking about competitive balance. Journal of Sports Economics, 4 (4), 255-279.

Treber, J., Levy, R., \& Matheson, V.A. (2013). Gender differences in competitive balance in intercollegiate basketball. In E.M. Leeds \& M.A. Leeds (Eds.). Handbook on the Economics of Women in Sports (pp. 251-268). Northhampton, MA: Edward Elgar. 